\title{
PEMURNIAN GLISERIN PRODUK SAMPING PRODUKSI BIODIESEL DENGAN METODE ASIDIFIKASI
}

\author{
Istnaeny Hudha M. ${ }^{1, *}$, Astuti Rahman N. ${ }^{1}$ \\ 1 Program Studi Teknik Kimia, Institut Teknologi Nasional, Jl. Bendungan Sigura-gura No. 2, Malang, 65152, \\ Indonesia \\ *Author Utama, email: istnaeny.hudha@gmail.com
}

\begin{abstract}
Glycerin is a major by-product of biodiesel production, with an amount of about $10 \%$ by weight of the biodiesel product. The growth of the biodiesel industry will trigger the production of glycerin, so it needs a method to increase its selling value. In general, the crude glycerine produced in the manufacture of biodiesel contains methanol, $\mathrm{KOH}$ catalysts, soaps, water and other substances. This purification process in addition to improving the purity of glycerin can also produce potassium which can be used as an alternative feeding material for fertilizer. One method of glycerin purification was investigated was the acidification process using several acids with grade pure analysis (p.a). The acidification process is carried out by reacting crude glycerin with an acid solution which will form a salt deposit. The resulting salt deposits are processed further so that Potassium fertilizer will be obtained. The obtained product is then analyzed the Potassium content. From the result of the research, the most optimum agitation time is 30 minutes with Potassium content of $64 \%$.
\end{abstract}

Keywords: glycerine, acidification, acid pure analysis, Potassium fertilizer

\section{ABSTRAK}

Gliserin merupakan produk samping utama pembuatan biodiesel, dengan jumlah sekitar 10\% berat dari produk biodiesel. Pertumbuhan industri biodiesel akan memicu produksi gliserin, sehingga dibutuhkan suatu metode untuk peningkatan nilai jualnya. Pada umumnya gliserin kasar yang dihasilkan dalam pembuatan biodiesel banyak mengandung metanol, katalis $\mathrm{KOH}$, sabun, air dan zat lainnya. Proses pemurnian ini selain dapat meningkatkan kemurnian dari gliserin juga dapat menghasilkan Potassium yang dapat dijadikan sebagai bahan baku alternatif pembuatan pupuk. Salah satu metode pemurnian gliserin diteliti adalah proses asidifikasi menggunakan beberapa asam dengan grade pure analysis (p.a). Proses asidifikasi dilakukan dengan mereaksikan gliserin kasar dengan larutan asam yang akan membentuk suatu suatu endapan garam. Hasil endapan garam yang dihasilkan diproses lebih lanjut sehingga akan diperoleh pupuk Potassium. Produk yang diperoleh kemudian dianalisa kandungan Potassiumnya Dari hasil penelitian diperoleh waktu pengadukan yang paling optimum adalah selama 30 menit dengan kadar Potassiumnya sebesar $64 \%$.

Kata Kunci: gliserin, acidification, asam pure analysis, pupuk Potassium

\section{PENDAHULUAN}

Biodiesel dihasilkan dari reaksi esterifikasi-transesterifikasi minyak nabati dan metanol berlebih dengan katalis basa $(\mathrm{KOH})$ dengan produk samping utama berupa gliserol, kelebihan metanol, katalis basa dan sabun. Diperkirakan gliserin yang dihasilkan sebanyak 10-15\% dari kapasitas produksinya dengan tingkat kemurnian sekitar
40-50\%. Konversi gliserin menjadi produk lain perlu dilakukan untuk menghindari timbulnya masalah lingkungan. Dengan demikian, sangat penting untuk memurnikan gliserin kasar guna menambah nilai aplikasi gliserin. Kemurnian tinggi gliserin juga penting sebagai bahan baku untuk berbagai aplikasi industri dalam makanan, kosmetik dan industri farmasi. Pupuk Potasium merupakan 
salah satu produk yang bisa diperoleh dari pemurnian gliserin kasar.

Kongjao, dkk (2010) melaporkan pemurnian gliserin kasar (30 wt \% konten gliserin) dari limbah bekas minyak nabati metil ester menggunakan 1,19 M H2SO4 diikuti oleh netralisasi dan ekstraksi pelarut untuk mendapatkan memurnikan gliserin kemurnian sekitar $93 \%$ berat . Dalam sebuah karya yang sama, Ooi TL, dkk (2001) menunjukkan bahwa gliserin kasar ditingkatkan dari kemurnian $34 \%$ berat sampai $52 \%$ berat dengan menggunakan asam sulfat . Akan Tetapi, masalah utama dalam proses ini adalah penggunaan asam sulfat yang memiliki sifat korosif asam sulfat dan non- biodegradabilitas garam sulfat yang dihasilkan.

Beberapa proses pemurnian gliserin yang telah dikembangkan di antaranya adalah proses pertukaran ion resin, teknologi nano-kavitasi, teknologi pemisahan membran (MST), distilasi sederhana, dan pengasaman (Acidification) diikuti oleh netralisasi dan ekstraksi pelarut dan lain-lain. Proses pemurnian gliserin menggunakan resin pertukaran ion (adsorpsi) dan distilasi sederhana terbatas karena proses ini umumnya menghasilkan hasil yang sangat rendah murni gliserin $(<15 \%$ berat). Penggunaan teknologi nano - kavitasi untuk pemurnian gliserin kasar telah dibuktikan , namun berskala besar yang operasi sangat menantang. MST bisa menghasilkan ultratinggi kemurnian gliserin dengan syarat gliserin kasar mengalami perlakuan guna mengurangi garam dan materi non organik gliserin (MONG, seperti metil ester). Dibandingkan dengan proses lainnya, proses menggunakan pengasaman lebih menjanjikan karena dihasilkan dengan kadar yang lebih tinggi dan biaya yang relatif rendah ${ }^{[22]}$.

Penelitian ini merupakan penelitian lanjutan sebelumnya yang mencoba untuk memurnikan gliserin dengan tiga jenis asam jenis pure analysys (p.a) yaitu asam sulfat, asam nitrat dan asam fosfat dengan berbagai jumlah mol. Selanjutnya akan diteliti proses pemurnian gliserin kasar dengan memvariasikan waktu proses reaksi pembentukan endapan menggunakan beberapa jenis asam yang berbeda untuk menyelidiki efek dari jenis asam. Adapun jenis asam yang digunakan antara lain asam sulfat (96 wt. \%), asam klorida (36 wt. \%), asam fosfat $(85 \%)$, asam nitrat (65 wt \%), asam klorida (36wt. \%) dan asam asetat. Endapan yang dihasilkan akan ditretment menjadi bahan baku pembuatan pupuk Potasssium

\section{METODE PENELITIAN}

\section{Material}

Material yang digunakan dalam penelitian ini meliputi mnyak kelapa sawit, metanol, $\mathrm{KOH}$, asam sufat $96 \%$, asam nitrat $65 \%$ dan asam fosfat $85 \%$.

\section{Peralatan}

Alat-alat yang digunakan dalam penelitian ini meliputi pendingin refluks, pemanas (heating mantle), stirer dan peralatan gelas lainnya. 


\section{Prosedur}

\section{Pembuatan Biodiesel}

Memanaskan minyak kelapa sawit sampai suhu $60^{\circ} \mathrm{C}$. Dalam tempat terpisah dicampur metanol dan $1 \%$ katalis dari massa minyak, kemudian dipanaskan sampai suhu yang sama, yakni suhu $60^{\circ} \mathrm{C}$, dengan perbandingan mol metanol dan minyak yaitu 6:1. Setelah mencapai suhu yang sama, keduanya dicampur dalam labu leher tiga, dan direfluks dengan kecepatan pengadukan 400 rpm selama 60 menit untuk menghasilkan metil ester dan gliserin kasar

\section{Pemurnian Gliserin}

$50 \mathrm{~mL}$ gliserin kasar pada suhu $40^{\circ} \mathrm{C}$, yang diperoleh dari hasil samping industri dengan katalis $\mathrm{KOH}$. Setelah itu, ditambahkan asam sulfat $96 \%$, asam nitrat $65 \%$, asam phosfat $85 \%$ pekat sesuai jumlah $\mathrm{ml}$ asam $(36 \mathrm{mmol}, 54 \mathrm{mmol}, 72 \mathrm{mmol}, 90$ $\mathrm{mmol}$ dan $108 \mathrm{mmol}$ ) sedikit demi sedikit sambil di aduk dengan pengaduk stirer 400 rpm, selama 30, 45 dan 60 menit. Larutan yang terbentuk kemudian didiamkan selama 30 menit. Setelah 30 menit terbentuk endapan, dimana endapan berada bawah dan gliserin murni dan asam lemak bebas diatas. Selanjutynya dianalisa kadar gliserin kasar, gliserin hasil pemurnian, $\mathrm{pH}$ dan jumlah endapan yang didapatkan.

\section{HASIL DAN PEMBAHASAN}

\section{Analisa Gliserin Kasar}

Gliserin hasil samping produksi biodiesel minyak kelapa sawit dengan katalis $\mathrm{KOH}$ merupakan satu fase yang mengandung banyak pengotor. Hasil analisis gliserin ditunjukkan dalam tabel 1.

Tabel 1. Hasil Analisa Gliserin Hasil Samping Biodiesel dari Minyak goreng bekas

\begin{tabular}{lc}
\hline \multicolumn{1}{c}{ Jenis Analisa } & Hasil \\
\hline $\mathbf{p H}$ & 10,00 \\
\hline Kadar KOH & $16,1261 \%$ \\
\hline Kadar Sabun (dalam K-Palmitat) & $11,6807 \%$ \\
\hline
\end{tabular}

Dari hasil analisa menunjukkan bahwa glserin kasar memiliki pH 10,00 yang bersifat basa. Hal ini disebabkan kandungan $\mathrm{KOH}$ dan sabunnya.

\section{Kadar Gliserin (\%)}

Dari hasil analisa diperoleh kandungan gliserin kasar sebesar 20,72 \%, sedangkan analisa kadar gliserin setelah proses asidifikasi dapat dilihat pada tabel 2. Dari hasil analisa menunjukkan bahwa proses pemurnian glierin kasar mampu menaikkan kemurnian gliserin, akan tetapu kadar yang dihasilkan masih memrlukan treatment lanjutan untuk menaikkan. Dimana hasil yang diperoleh paling tinggi berkisar $64 \%$.

\section{Derajat Keasaman (pH) Gliserol}

Pengamatan drajat keasaman $(\mathrm{pH})$ gliserol dilakukan pada saat pemurnian gliserol dengan konsentrasi asam sesuai dengan variabel berubahnya. Data hasil pengamatan $\mathrm{pH}$ ditunjukkan pada Tabel 3 . Proses reaksi antara gliserin kasar dengan berbagai jenis asam menghasilkan penurunan $\mathrm{pH}$ dari tinggi ke rendah. 
Tabel 2. Hasil Analisa Gliserin Hasil Samping Biodiesel dari Minyak goreng bekas

\begin{tabular}{|c|c|c|c|c|c|c|}
\hline \multirow{2}{*}{ Jenis asam } & \multirow{2}{*}{ Waktu (men) } & \multicolumn{5}{|c|}{ Kadar Gliserin (\%) pada berbagai konsentrasi asam } \\
\hline & & $36 \mathrm{mmol}$ & $54 \mathrm{mmol}$ & $72 \mathrm{mmol}$ & $90 \mathrm{mmol}$ & $108 \mathrm{mmol}$ \\
\hline \multirow{3}{*}{$\begin{array}{l}\text { Asam Sulfat } 96 \% \\
\qquad\left(\mathrm{H}_{2} \mathrm{SO}_{4}\right)\end{array}$} & 30 & 32,85 & 38,25 & 45,23 & 48,35 & 64,00 \\
\hline & 45 & 30,22 & 36,38 & 61,24 & 62,25 & 63,25 \\
\hline & 60 & 25,65 & 33,25 & 55,65 & 60,35 & 63,00 \\
\hline \multirow{3}{*}{$\begin{array}{l}\text { Asam Fosfat } 85 \% \\
\left(\mathrm{H}_{3} \mathrm{PO}_{4}\right)\end{array}$} & 30 & 41,90 & 46,51 & 33,61 & 47,65 & 64,00 \\
\hline & 45 & 35,45 & 37,35 & 39,50 & 42,00 & 60,24 \\
\hline & 60 & 30,25 & 32,70 & 40,25 & 45,58 & 46,50 \\
\hline \multirow{3}{*}{$\begin{array}{c}\text { Asam Nitrat 65\% } \\
\left(\mathrm{HNO}_{3}\right)\end{array}$} & 30 & 12,40 & 14,27 & 10,59 & 14,30 & 25,32 \\
\hline & 45 & 21,64 & 22,69 & 24,00 & 25,65 & 25,25 \\
\hline & 60 & 28,25 & 34,28 & 39,25 & 52,03 & 42,82 \\
\hline \multirow{3}{*}{$\begin{array}{c}\text { Asam Klorida } 36 \% \\
(\mathrm{HCl})\end{array}$} & 30 & 32,25 & 36,45 & 37,30 & 45,95 & 47,96 \\
\hline & 45 & 30,85 & 16,12 & 32,45 & 35,24 & 37,80 \\
\hline & 60 & 24,54 & 24,54 & 30,20 & 28,38 & 30,35 \\
\hline \multirow{3}{*}{$\begin{array}{l}\text { Asam Asetat } \\
\left(\mathrm{CH}_{3} \mathrm{COOH}\right)\end{array}$} & 30 & 20,70 & 20,70 & 20,72 & 20,72 & 20,72 \\
\hline & 45 & 20,70 & 20,70 & 20,72 & 20,72 & 20,72 \\
\hline & 60 & 20,70 & 20,70 & 20,72 & 20,72 & 20,72 \\
\hline
\end{tabular}

Tabel 3. Data Pengamatan Derajat Keasaman $(p H)$ Gliserin

\begin{tabular}{|c|c|c|c|c|c|c|}
\hline \multirow[t]{2}{*}{ Jenis asam } & \multirow{2}{*}{$\begin{array}{l}\text { Waktu } \\
\text { (men) }\end{array}$} & \multicolumn{5}{|c|}{ pH gliserol pada berbagai konsentrasi asam } \\
\hline & & $36 \mathrm{mmol}$ & $54 \mathrm{mmol}$ & $72 \mathrm{mmol}$ & $90 \mathrm{mmol}$ & $108 \mathrm{mmo}$ \\
\hline \multirow{3}{*}{$\begin{array}{c}\text { Asam Sulfat } 96 \% \\
\left(\mathrm{H}_{2} \mathrm{SO}_{4}\right)\end{array}$} & 30 & 0,6 & 0,4 & 0,4 & 0,3 & 0,2 \\
\hline & 45 & 0,6 & 0,4 & 0,4 & 0,3 & 0,2 \\
\hline & 60 & 0,6 & 0,4 & 0,4 & 0,3 & 0,2 \\
\hline \multirow{3}{*}{$\begin{array}{l}\text { Asam Fosfat 85\% } \\
\left(\mathrm{H}_{3} \mathrm{PO}_{4}\right)\end{array}$} & 30 & 1,2 & 1 & 0,9 & 0,9 & 0,8 \\
\hline & 45 & 1,2 & 1 & 0,9 & 0,9 & 0,8 \\
\hline & 60 & 1,2 & 1 & 0,9 & 0,9 & 0,8 \\
\hline \multirow{3}{*}{$\begin{array}{c}\text { Asam Nitrat 65\% } \\
\left(\mathrm{HNO}_{3}\right)\end{array}$} & 30 & 0,6 & 0,4 & 0,3 & 0,3 & 0,2 \\
\hline & 45 & 0,6 & 0,4 & 0,3 & 0,3 & 0,2 \\
\hline & 60 & 0,6 & 0,4 & 0,3 & 0,3 & 0,2 \\
\hline \multirow{3}{*}{$\begin{array}{c}\text { Asam Klorida } 36 \% \\
\text { (HCl) }\end{array}$} & 30 & 0,7 & 0,5 & 0,4 & 0,4 & 0,3 \\
\hline & 45 & 0,8 & 0,5 & 0,4 & 0,4 & 0,4 \\
\hline & 60 & 0,7 & 0,5 & 0,4 & 0,4 & 0,3 \\
\hline \multirow{3}{*}{$\begin{array}{c}\text { Asam Asetat } \\
\left(\mathrm{CH}_{3} \mathrm{COOH}\right)\end{array}$} & 30 & 4,4 & 4,1 & 3,9 & 3,8 & 3,7 \\
\hline & 45 & 4,4 & 4,1 & 4 & 3,8 & 3,7 \\
\hline & 60 & 4,4 & 4,1 & 3,9 & 3,8 & 3,7 \\
\hline Gliserol kasar & \multicolumn{6}{|c|}{10} \\
\hline
\end{tabular}

Tabel 4. Data Hasil Pengamatan Endapan Garam (g)

\begin{tabular}{|c|c|c|c|c|c|c|}
\hline \multirow{2}{*}{ Jenis asam } & \multirow{2}{*}{ Waktu (men) } & \multicolumn{5}{|c|}{ Jumlah Endapan (gram) pada berbagai konsentrasi asam } \\
\hline & & $36 \mathrm{mmol}$ & $54 \mathrm{mmol}$ & $72 \mathrm{mmol}$ & $90 \mathrm{mmol}$ & $108 \mathrm{mmol}$ \\
\hline \multirow{3}{*}{$\begin{array}{l}\text { Asam Sulfat } 96 \% \\
\qquad\left(\mathrm{H}_{2} \mathrm{SO}_{4}\right)\end{array}$} & 30 & 2,63 & 2,57 & 2,52 & 2,47 & 2,35 \\
\hline & 45 & 0,43 & 0,59 & 0,74 & 0,73 & 0,53 \\
\hline & 60 & 0,41 & 0,52 & 0,58 & 0,46 & 0,55 \\
\hline \multirow{3}{*}{$\begin{array}{c}\text { Asam Fosfat } \\
85 \% \\
\left(\mathrm{H}_{3} \mathrm{PO}_{4}\right)\end{array}$} & 30 & 2,31 & 2,36 & 2,25 & 2,21 & 1,84 \\
\hline & 45 & 0,74 & 0,87 & 0,80 & 0,57 & 0,69 \\
\hline & 60 & 0,55 & 0,86 & 0,81 & 0,73 & 0,71 \\
\hline \multirow{3}{*}{$\begin{array}{c}\text { Asam Nitrat 65\% } \\
\left(\mathrm{HNO}_{3}\right)\end{array}$} & 30 & 3,74 & 4,26 & 4,15 & 3,9 & 3,74 \\
\hline & 45 & 0,58 & 0,60 & 0,39 & 0,43 & 0,46 \\
\hline & 60 & 0,53 & 0,47 & 0,55 & 0,51 & 0,55 \\
\hline \multirow{3}{*}{$\begin{array}{c}\text { Asam Klorida } \\
36 \% \\
(\mathrm{HCl})\end{array}$} & 30 & 0,16 & 0,20 & 0,24 & 0,26 & 0,06 \\
\hline & 45 & 0,17 & 0,20 & 0,23 & 0,2 & 0,03 \\
\hline & 60 & 0,11 & 0,21 & 0,12 & 0,05 & 0,14 \\
\hline \multirow{3}{*}{$\begin{array}{c}\text { Asam Asetat } \\
\left(\mathrm{CH}_{3} \mathrm{COOH}\right)\end{array}$} & 30 & 0 & 0 & 0 & 0 & 0 \\
\hline & 45 & 0 & 0 & 0 & 0 & 0 \\
\hline & 60 & 0 & 0 & 0 & 0 & 0 \\
\hline
\end{tabular}




\section{Endapan Garam yang Dihasilkan pada Pemurnian Gliserol}

Perlakuan netralisasi basa dan pemecahan sabun dengan asam mineral pada pemurnian gliserol berhasil membentuk endapan garam. Data hasil pengamatan endapan garam (kering) ditunjukkan pada Tabel 4. Proses terbentuknya endapan garam dipengaruhi reaksi asam kuat - basa kuat, dengan semakin bertambahnya konsentrasi asam maka endapan garam akan mengalami kecenderungan penurunan setelah berada di titik optimum yang disebabkan oleh meningkatnya kelarutan garam dalam gliseri. Hal ini disebabkan meningkatnya kadar air hasil reaksi dehidrasi. Jumlah endapan hasil reaksi asam nitrat lebih besar karena Garam kalium nitrat memiliki kelarutan dalam gliserol yang lebih baik dari pada garam lainnya. Selain itu, garam (dalam keadaan asam) dan asam nitrat merupakan oksidator kuat terhadap molekul organik.

\section{KESIMPULAN}

Proses pemurnian gliserin produk samping pembuatan biodiesel memperoleh kemurnian yang paling tinggi sebesar $64 \%$ dengan waktu pengadukan selama 30 menit.

\section{UCAPAN TERIMAKASIH}

Pada kesempatan ini, penulis menyampaikan ucapan terima kasih Ristek Dikti yang telah membiayai penelitian ini. Tak lupa kami sampaikan terima kasih juga kepada pimpinan di lingkungan ITN Malang khususnya LPPM ITN, Program Studi Teknik Kimia yang telah memfasilitasi penelitian ini

\section{DAFTAR PUSTAKA}

[1] Afif Aufari M., Sia Robianto, Renita Manurung. 2013. Pemurnian Crude Glycerine Melalui Proses Bleaching Dengan Menggunakan Karbon Aktif. Jurnal Teknik Kimia USU, Vol. 2, No. 1

[2] Alamu, O.J., M.A. Waheed, dan S.O. Jekayinfa. (2007). Alkali-catalysed Laboratory Production and Testing of Biodiesel Fuel from Nigerian Palm Kernel Oil. The CIGR EjournalEE 07009 (IX) July 2007: 1-7

[3] Aziz, I., Siti Nurbayti, Fira Luthfiana. (2008). Pemurnian Gliserin Dari Hasil Samping Pembuatan BiodieselMenggunakan Bahan Baku Minyak Goreng Bekas. Valensi Vol. 1 No. 3, (157-162)

[4] Bacovsky, D., W. Körbitz, M. Mittelbach, dan M. Wörgetter. (2007). Biodiesel Production: Technologies and European Providers. IEA Task 39 Report T39-B6.

[5] Behr A, Eilting J, Irawadi K, Leschinski J, Lindner F. (2008), Improved utilization of renewable resources: New important derivatives of glycerol. Green Chemistry. 2008; 10: 13-30.

[6] Enilson de BR, Elton $\mathrm{NH}$, Paulo HG, Jose DF, Alessandro TC, (2015). Glycerin effluent from the biodiesel industry as potassium source to fertilize soybean crop, African journal of agricultural research, vol 10 (13), pp 1572-1580, 26 March, 2015

[7] Fanani. 2010. Kajian Pemurnian Gliserin Hasil Samping Biodiesel Jarak Pagar Menggunakan AsamNitrat, Sulfat, dan Fosfat, Skripsi, tidak diterbitkan, Fakultas Teknologi Pertanian, Institut Pertanian Bogor

[8] Ferreira MO, deSousa EMBD, Pereira CG. (2013), International Journal of Chemical Reactor Engineering. 11: 1-8.

[9] Gerpen, J.V. (2005). Biodiesel Processing and Technology. Fuel Processing Technology 86: 1097 $-1107$

[10] Hazimah A H, Ooi TL, Salmiah A. (2013), Recovery ofglycerol and diglycerol from glycerol pitch. Journal of Oil Palm Research. 15: 1-5.

[11] Hudha, M.I., Wijaya J. F., Simanjuntak T. (2015) Pemurnian gliserin kasar menggnakan proses adsorpsi dengan variasi adsorben dan kecepatan pengadukan, Penelitian, Teknik Kimia ITN Malang

[12] Hudha, z.I., Dyba A. P., Firdiansyah F., (2015) Pemanfaatan sisa katalis $\mathrm{KOH}$ dalam gliserin hasil samping biodiesel menjadi pupuk kalium dengan variasi asam dan konsentrasi asam, Penelitian, Teknik Kimia ITN Malang

[13] Javani A, Hasheminejad $M$, Tahvildari $K$, Tabatabaei M. (2012), High quality potassium phosphate production through step-by-step glycerol purification: A strategy to economize biodiesel production, Bioresour Technol.104: 788-790.

[14] Jimmy, Hudha, M. I., Minah, F.N., (2015) Pembuatan gliserin karbonat dari gliserin (hasil samping industry biodiesel) denganvariasi rasio reaktan dan waktu reaksi, Penelitian, Teknik Kimia ITN Malang

[15] Johnson DT, Taconi KA (2007), The glycerol glut: Options for the value-added conversion of crude glycerol resulting from biodiesel production. Environ. Prog. 26: 338-348.

[16] Kocsisová, T. dan J. Cvengroś. (2006). G-Phase form Methyl Ester Production - Splitting and Refining. Petroleum \& Coal48 (2): $1-5$ 
[17] Kongjao S, Damronglerd S, Hunsom M. (2010), Purification of crude glycerol derived from waste used-oil methyl ester plant, Korean J Chem Eng. 27: 944- 949

[18] Manosak R, Limpattayanate S, Hunsom M. (2011), Sequential-refining of crude glycerol derived from waste used-oil methyl ester plant via a combined process of chemical and adsorption. Fuel Process. Technol. 92: 92-99.

[19] Hajek M., Skopal F., (2009) Purification of glycerol phase after transesterification of vegetable oils, $44^{\text {th }}$ international petroleum conference, Bratislava, Slovak Republic, September 21-222, 2009

[20] McCoy M. (2006), Glycerol surplus: Plants are closing and New Uses for the chemical are being found. Chem Eng News. 84: 7.

[21] Muyassaroh, Daryono, E. D., Hudha, M. I., (2012). Biodiesel dari Minyak jarak pagar dengan variasi penambahan Co-solvent dan waktu reaksi, Jurnal Teknik Kimia, Volume 7, No. 1. Pp 8-11

[22] Nanda MR, Yuan Z, Qin W, Poirier M, Chunbao X. (2014), Purification of crude glycerol using acidification : Effects of acids types and product characterization, Austin Journal of Chhemical Engineering

[23] Ooi TL, Yong KC, Dzulkefly K Wanyunus WMZ, Hazimah AH. (2001), Crude glycerine recovery from glycerol residue waste from a palm kernel oil methyl ester plant. J Oil Palm Res. 13: 16-22.

[24] Roy, A.H. (2007). Fertilizer and Food Production. Didalam J.A. Kent (Ed.). Kent and Riegel's Handbook of Industrial Chemistry and Biotechnology. Edisi 11. New York: Springer

[25] Setyaningsih Dwi, Hambali, E., Farobie O., (2007). Pembuatan pupuk potassium dari proses pemurnian gliserin hasil samping industry biodiesel, Konferensi Nasional 2007. Jakarta 13 Maret 2007 